\title{
Primary adenocarcinoma of the jejunum in elderly patient
}

\author{
Hakan Demirci • Guldem Kilciler • \\ Murat Kantarcioglu $\cdot$ Zulfikar Polat • \\ Ahmet Uygun · Sait Bagci
}

Received: 19 January 2014/ Accepted: 5 March 2014/Published online: 14 March 2014

(C) Springer International Publishing Switzerland 2014

To the Editor,

Primary neoplasm of the small bowel is very rare. This constitutes $7-8 \%$ of all tumours of gastrointestinal tract and only $1 \%$ of the malignant ones [1]. Adenocarcinoma is the most common histolopathologic subtype of carcinoma of the small bowel [2]. Adenocarcinoma risk increases with progressing age. Adults older than 65 years demonstrate an increased prevalence of small bowel carcinoma. Herein, we report of an unusual and rare case with jejunal adenocancer. A 66-year-old man was presented to the gastroenterology outpatient clinic for iron deficiency anemia symptoms such as weakness, fatigue, and palpitation. His physical examination did not show any pathologic signs. Laboratory analysis showed hemoglobin: $10 \mathrm{~g} / \mathrm{dL}$, ferritin: 0.9 (22-322) ng/dL, iron: $24(53-167) \mathrm{mcg} / \mathrm{dL}$, total iron binding capacity: $418(155-300) \mu \mathrm{g} / \mathrm{dL}$ and normal electrolyte panel values. Abdominal ultrasound was normal. Performed esophagogastroduodenoscopy and colonoscopy revealed no pathology. Capsule endoscopy confirmed

\footnotetext{
H. Demirci $(\varangle) \cdot$ G. Kilciler · M. Kantarcioglu · Z. Polat ·

A. Uygun $\cdot$ S. Bagci

Department of Gastroenterology, Gulhane Military Medical

Academy, 06108 Etlik, Ankara, Turkey

e-mail: hakandemircigata@yahoo.com

G. Kilciler

e-mail: gkilciler@gata.edu.tr

M. Kantarcioglu

e-mail: kantarci@hotmail.com

Z. Polat

e-mail: zulfikar.polat@gmail.com

A. Uygun

e-mail: ahmetuygun62@hotmail.com

S. Bagci

e-mail: saitbagci@yahoo.com
}

jejunal ulcer. Double balloon enteroscopy demonstrated this lesion which causes narrowness of the lumen of the jejunum and endoscopic biopsy was performed. Histopathological examination confirmed the presence of adenocarcinoma. Computerized tomography scan of the abdomen with intravenous and oral contrast showed no pathology. Surgical resection was performed. After 3 months, whole body positron emission tomography scan was normal. Small intestine adenocancer is a rare tumor and to our knowledge a barely published elderly cases in the literature. Because small intestine is relatively unattainable with routine endoscopy, most of the patients are diagnosed in advanced stage. A precise and early diagnosis is crucial. This is the most important prognostic factor for curative radical surgery [3]. Consequently, when a small bowel neoplasm is doubted, capsule endoscopy and double balloon enteroscopy are the most useful techniques [4].

Conflict of interest All authors have no potential conflict of interests.

\section{References}

1. Awrich AE, Irish CE, Vetto RM, Fletcher WS (1980) A twentyfive year experience with primary tumors of the small intestine. Surg Gynecol Obstet 151(1):9-14

2. Landis SH, Murray T, Bolden S, Wingo PA (1999) Cancer statistics. CA Cancer J Clin 49(1):8-31

3. Morgan DF, Busuttil RW (1984) Primary adenocarcinoma of the small intestine. Am J Surg 147:331-333

4. Yamamoto H, Sekine Y, Sato Y et al (2001) Total enteroscopy with a nonsurgical steerable double-balloon method. Gastrointest Endosc 53(2):216-220 